${ }^{1}$ CNRM/GAME, Météo-France/CNRS, Toulouse, France

${ }^{2}$ Deutsches Zentrum für Luft- und Raumfahrt (DLR), Institut für Physik der Atmosphäre, Oberpfaffenhofen, Germany

${ }^{3}$ National Aerospace Laboratory (NLR), Amsterdam, The Netherlands

${ }^{4}$ Direction de la Prévision (Météo-France), Toulouse, France

\title{
Description of convective-scale numerical weather simulation use in a flight simulator within the Flysafe project
}

\author{
S. Pradier-Vabre ${ }^{1}$, C. Forster ${ }^{2}$, W. W. M. Heesbeen ${ }^{3}$, C. Pagé $^{4}$, S. Sénési ${ }^{4}$, A. Tafferner ${ }^{2}$, \\ I. Bernard-Bouissières ${ }^{4}$, O. Caumont ${ }^{1}$, A. Drouin ${ }^{4}$, V. Ducrocq ${ }^{1}$, Y. Guillou ${ }^{4}$, P. Josse ${ }^{4}$
}

With 7 Figures

Received 31 October 2007; Accepted 9 April 2008

Published online 20 August 2008 (C) Springer-Verlag 2008

\begin{abstract}
Summary
Within the framework of the Flysafe project, dedicated tools aiming at improving flight safety are developed. In particular, efforts are directed towards the development of the Next Generation-Integrated Surveillance System (NG-ISS), i.e. a combination of new on-board systems and ground-based tools which provides the pilot with integrated information on three risks playing a major role in aircraft accidents: collision with another aircraft, collision with terrain, and adverse weather conditions. For the latter, Weather Information Management Systems (WIMSs) based on nowcasts of atmospheric hazards are developed.

This paper describes the set-up of a test-bed for the NGISS incorporating two types of WIMS data, those related to aircraft in-flight icing and thunderstorm risks. The test-bed is based on convective-scale numerical simulations of a particular weather scenario with thunderstorms and icing in the area of the Innsbruck airport. Raw simulated fields as well as more elaborate diagnostics (synthetic reflectivity and satellite brightness temperature) feed both the flight simulator including the NG-ISS and the algorithms in charge of producing WIMS data. WIMS outputs based on the synthetic data are discussed, and it is indicated that the high-resolution simu-
\end{abstract}

Correspondence: Olivier Caumont, Météo-France/CNRS, 42 av. Coriolis, 31057 Toulouse Cedex, France (E-mail: olivier.caumont@ meteo.fr) lated fields are beneficial for the NG-ISS test-bed purposes and its technical feasibility.

\section{Introduction}

The present work is conducted within the scope of Flysafe (www.eu-Flysafe.org/), a 4year Integrated Project of the 6th framework of the European Commission started on February 2005. The Flysafe project aims to increase flight safety by improving information supplied to flight crew members. The aim is to develop, implement and validate the Next GenerationIntegrated Surveillance System, i.e. a combination of new on-board systems and ground-based tools which will allow pilots to have an accurate and homogeneous view of the aircraft safety situation during all phases of flight. It is designed to relay information connected to the main causes of accidents around the world: traffic and ground collisions, and adverse weather conditions (ACARE 2002). Regarding this last item, specialized tools for generating nowcasts of atmospheric hazards are developed: the Weather Information Management Systems. Four WIMS types feeding the 
NG-ISS are defined, each tackling one hazard: wake vortices, clear air turbulence, thunderstorms (CB), and aircraft in-flight icing (ICE). Only the last two ones are addressed here.

This paper describes how new weather information can be used in an existing full flight simulator (FFS), in order to implement the test-bed dedicated to the NG-ISS developed in Flysafe. By flying the FFS, pilots will make it possible to test the technical feasibility of the whole system and evaluate the usefulness of such new information. The FFS including the NG-ISS as well as the algorithms producing the WIMS data are supplied with a high-resolution simulation of severe weather. This numerical simulation, as source for all components of meteorological products in the cockpit (WIMS as well as onboard radar information from the FFS), provides a consistent data set enabling comparison of all these products. The Mesoscale Alpine Program (MAP, Bougeault et al. 2001) Intensive Observing Period 2B (IOP2B) precipitation event provides the weather scenario. The MAP field campaign (7 September to 15 November 1999) took place over the Alps. It resulted from a coordinated effort to explore and understand the mesoscale effects of complex topography on meteorological events such as heavy precipitation and downslope windstorms that can cause significant damage and constitute threats to aviation. Thus, the IOP2B precipitating event provides the opportunity to test the NG-ISS with respect to two risks at the same time: adverse weather and complex terrain.

The following section presents the general data flow chart for the evaluation process of the WIMS and the NG-ISS regarding weather hazards. Section 3 details both the MAP IOP2B case and the high-resolution simulation. In Sects. 4 and 5 , the processing of simulated data by the FFS, and by the CB and ICE WIMSs is described. Finally, a discussion about NG-ISS test-bed assets and expected benefits from its implementation concludes the paper.

\section{Set-up of the NG-ISS test-bed regarding weather hazards}

Figure 1 shows the data flow chart feeding the FFS (top right box). The FFS is a virtual cockpit in which the NG-ISS was set up. A high-resolution numerical simulation (top left box) provides synthetic data for both surface-based weather centre (bottom box) and cockpit. On the one hand, simulated meteorological parameters are used to produce standard meteorological observed and forecast products (METAR $^{1}$, SIGMET $\left.^{2}, \ldots\right)$ and synthetic CB and ICE WIMSs which are sent to the FFS including the NG-ISS. On the other hand, meteorological simulations feed the Airborne Doppler Weather Radar (ADWR) database and another FFS component which manages the atmospheric observations available on-board and the flight aerodynamic aspect. Thus, the flight crew in the FFS should have access to consistent on-board weather radar data and hazard nowcasts, as these are based on same original synthetic data. Simulated meteorological data are supplied for the Innsbruck Terminal Manoeuvring Area (TMA, an area of approximately $200 \times 200 \mathrm{~km}$ defined for the FFS on Fig. 2b) for the 20 September 1999 during MAP IOP2b. From an aeronautical point of view, this case is interesting on two counts: the pilot has to cope with both bad weather and complex terrain.

\section{Numerical weather simulation}

MAP-IOP2B lasted 2 days (19 and 20 September). It is one of the most intense rainfall episodes during the MAP field campaign which allowed to perform studies on both "wet" and "dry" MAP events. It has been largely analysed based on observations and atmospheric modelling. IOP2B orographic precipitation record the largest number of papers; whose main conclusions were combined and discussed by Rotunno and Houze (2007).

The Meso-NH research mesoscale non-hydrostatic model (Lafore et al. 1998) is used here to simulate this case. Meso-NH was previously run on the same IOP to study both the Foehn in the Rhine Valley (Jaubert and Stein 2003), and the precipitation over the entire two-day period (Asencio et al. 2003). Here, the same numerical set-up is used: 2-way nested configuration with three domains at $10,2.5$ and $1 \mathrm{~km}$ resolution, respectively. The outer domain is the one of Asencio et al. (2003), whereas the two inner do-

\footnotetext{
${ }^{1}$ METAR: METeorological Airport Report, report on meteorological observations

${ }^{2}$ SIGMET: SIGnificant METeorological Information, meteorological information both observed and forecasted
} 


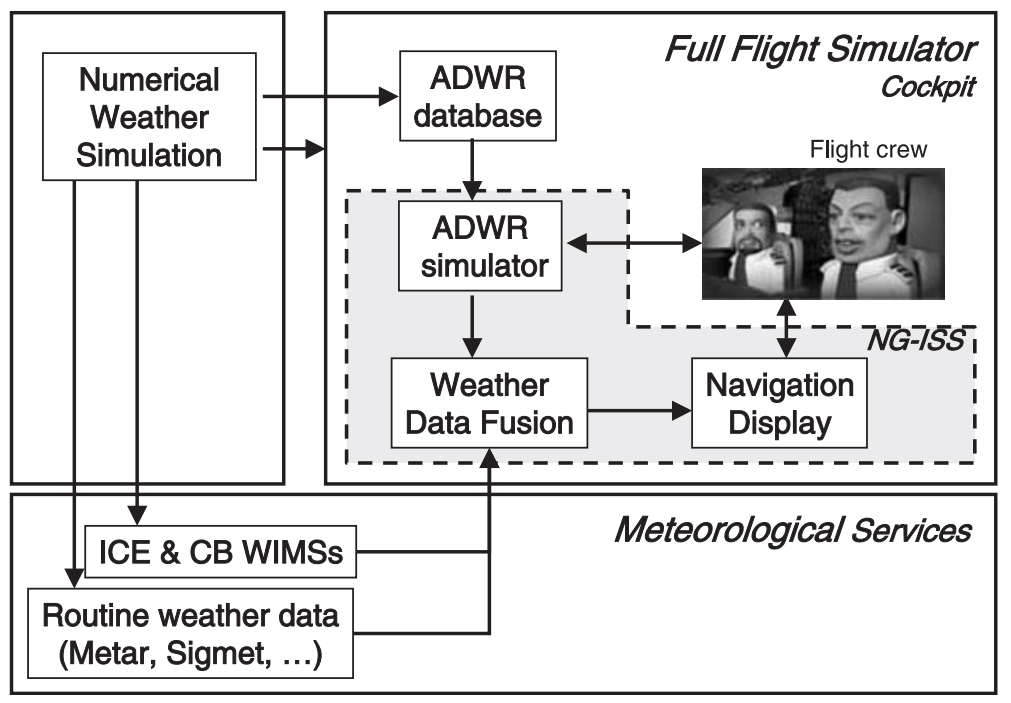

Fig. 1. Concept of the NG-ISS test-bed related to weather information (grey filled frame). The upper right box represents the FFS. The twoother boxes represent the input to the FFS mains have been shifted to include the Innsbruck airport, located in the east-west oriented Inn valley (Fig. 2).

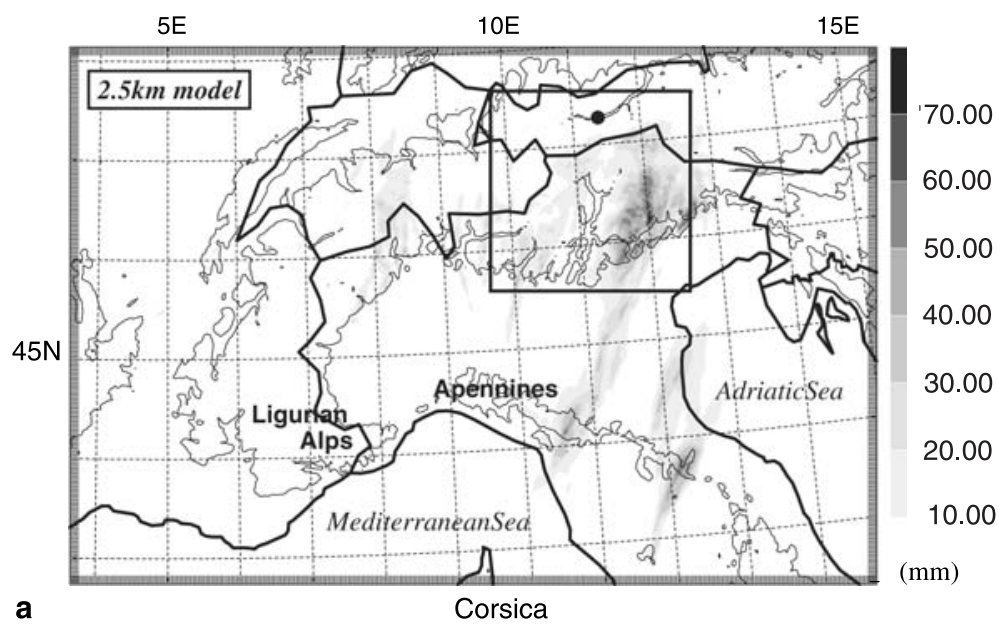

60.00

50.00

40.00

30.00

20.00

0.00
The synoptic situation is a MAP typical one: an eastward drifting front and associated moist southerly flow impinging on the Alps. a

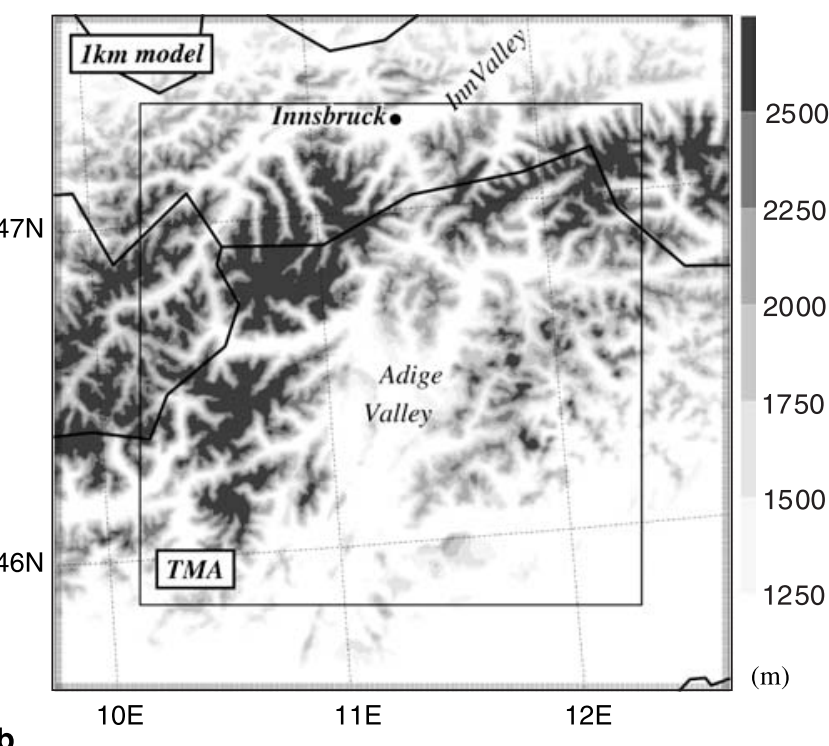

Fig. 2. Inner nested-model domains with geographical references. (a) $2.5 \mathrm{~km}$ mesh model domain. The grey scale shows the cumulated rain $(\mathrm{mm})$ between 1330 and 1600 UTC on 20 September 1999. The solid line square represents the $1 \mathrm{~km}$ domain. The black point indicates Innsbruck airport. (b) Orography of the $1 \mathrm{~km}$ domain (grey scale, (m)). The solid line square represents the TMA (as used for Innsbruck in the FFS) 
Southerly airstream first lost moisture over coastal mountains (i.e., the Ligurian Alps and the Apennines), then over the main Alps massif. The Meso-NH simulation starts at 1200 UTC on 20 September. We focus here on the 13301600 UTC time window corresponding to the rainy period for the Innsbruck region. At that time, the front has crossed the western part of the Alps chain. The associated low-level jet is located to the east of Corsica and generates first precipitation over the Apennines. Thunderstorms develop and are transported in a south-westerly mid-tropospheric flow (Asencio et al. 2003; Smith et al. 2003). Rainfall is then strengthened over the Alpine relief, highlighting a strong orographic forcing as suggested by Fig. 2a. Focusing on the smallest domain (Fig. 2b), precipitation over the eastern slopes are also fed by a low-level moist south-easterly flow from the Adriatic Sea. Consequently, precipitating cells are located over the south upwind slopes as revealed by the comparison of Figs. 2b and 3. Convective cells triggered and/or enhanced by orography are embedded in a larger precipitating system. Maximum altitude of simulated convective cloud top is $200 \mathrm{hPa}$. Primary ice is found above the $0{ }^{\circ} \mathrm{C}$-level located at about $600 \mathrm{hPa}$. Snow and graupel particles are also simulated above the $700 \mathrm{hPa}$ level (not shown). Although Innsbruck is outside the heaviest precipitating area, a southerly aircraft approach towards the airport can turn out to be delicate. Moreover, as mentioned above, Foehn and gravity waves events in the northern Alpine part were also analysed during the IOP2B (in particular, Meso-NH reproduces a Foehn event in the Inn Valley on the 20th afternoon, not

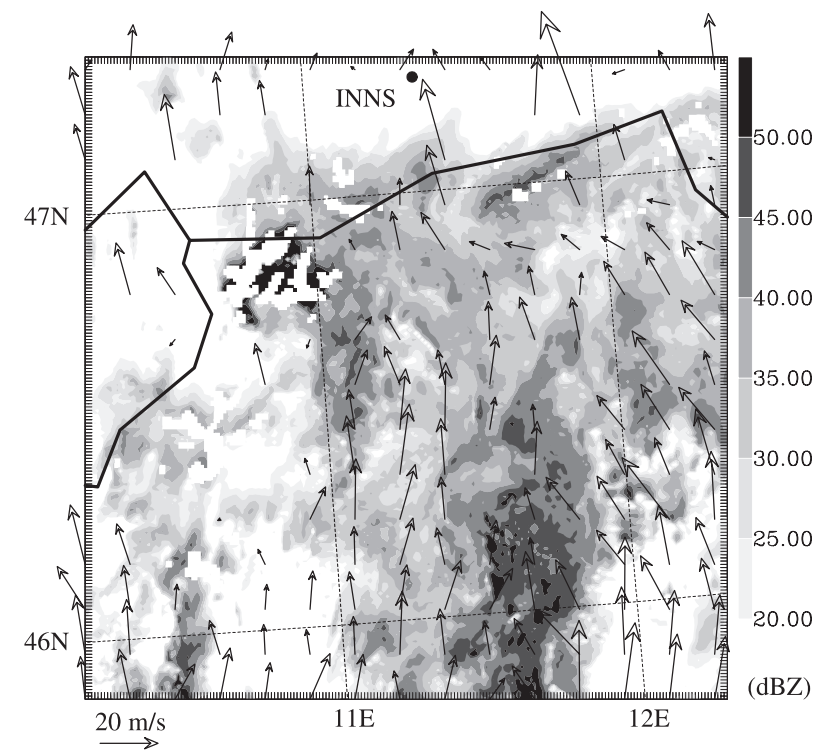

Fig. 3. Simulated reflectivity fields (grey scale (dBZ)) at $700 \mathrm{hPa}$ and wind vectors at $800 \mathrm{hPa}$ at $1400 \mathrm{UTC}$ on 20 September 1999 over the TMA area (defined on Fig. 2b). The black point indicates Innsbruck airport

shown). The dynamics associated with these phenomena can be dangerous for aircraft and urge the pilot to considerably change the flight track.

Table 1 lists the Meso-NH meteorological parameters provided to the FFS and WIMS algorithms. CB WIMS considers cumulonimbus as described by different processes occurring in the upper (top volume) and lower (bottom volume) troposphere. These two volumes are processed separately, as described in Sect. 5. It can be noticed from Table 1 that FFS, including standard cockpit atmospheric probes, and ADWR need high temporal and spatial resolutions, as well as CB WIMS bottom volume diagnostics,

Table 1. Meso-NH output parameters delivered to FFS components and to WIMS algorithms. Spatial and temporal resolutions are also indicated. FFS other refers to parameters from the Meso-NH model needed to simulate flight atmospheric conditions, including informations provided by standard airborne atmospheric probes

\begin{tabular}{|c|c|c|c|c|}
\hline \multicolumn{3}{|c|}{$\begin{array}{l}1 \mathrm{~km} \text { domain } \\
\Delta \mathrm{t}=5 \mathrm{~min}, \Delta x=1 \mathrm{~km}\end{array}$} & \multicolumn{2}{|l|}{$\begin{array}{l}2.5 \mathrm{~km} \text { domain } \\
\Delta \mathrm{t}=15 \mathrm{~min}, \Delta x=2.5 \mathrm{~km}\end{array}$} \\
\hline ADWR & FFS other & CB WIMS Bottom volume & CB WIMS Top volume & ICE WIMS \\
\hline $\begin{array}{l}\text { Reflectivity } \\
\text { 3D wind } \\
\text { components }\end{array}$ & 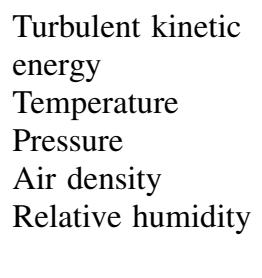 & $\begin{array}{l}\text { Vertically integrated } \\
\text { liquid water } \\
\text { Altitude of reflectivity } \\
\text { maximum } \\
\text { Reflectivity maximum } \\
18 \mathrm{dBZ} \text { altitude }\end{array}$ & $\begin{array}{l}\text { Temperature } \\
\text { Pressure } \\
\text { IR brightness temperature } \\
\text { WV brightness temperature }\end{array}$ & $\begin{array}{l}\text { Reflectivity } \\
\text { IR brightness } \\
\text { temperature } \\
\text { Vertical wind component } \\
\text { Surface temperature } \\
\text { Temperature } \\
\text { Relative humidity }\end{array}$ \\
\hline
\end{tabular}


which partly rely on Doppler radar observations. On the other hand, regarding ICE WIMS and CB WIMS top volume diagnostics based on satellite information, a coarser resolution is sufficient, both on temporal and spatial scales. Thus, Meso-NH outputs were issued at 15 and $5 \mathrm{~min}$ time steps over the $2.5-\mathrm{km}$ and $1-\mathrm{km}$ domains, respectively. Simulated radar reflectivity data were retrieved using a grid-point radar simulator (Richard et al. 2003), and a radiative transfer scheme adapted from the Radiative Transfer for Television and Infrared Observation Satellite Operational Vertical Sounder (RTTOV) (Chaboureau and Bechtold 2005) allowed to simulate Infra-Red (IR) and Water Vapour (WV) brightness temperatures, according to Meso-NH simulated hydrometeors (cloud water, rainwater, snow, primary ice, and graupel) and temperature.

\section{Synthetic data processing by the full flight simulator (FFS)}

The research full flight simulator named GRACE (Heesbeen et al. 2006) has a unique modular architecture which allows both great versatility and simulations with a high level of realism. A lot of research specific software and hardware can be integrated into GRACE with low effort and in a short time. This is why it has been selected to evaluate the NG-ISS, regarding weather hazards in the scope of this paper. For this last purpose, FFS configuration is schematized in the right box of Fig. 1. The ADWR simulator provides outputs directly available for pilots on the Navigation Display. At the same time, ADWR outputs are merged with WIMS products and standard meteorological messages through the Weather Data Fusion module. Weather Data Fusion manages all the weather data and supplies the Navigation Display with elaborate products. It ensures, for example, the consistency between external (WIMSs, METAR, SIGMET, ... ) and onboard (ADWR, cockpit atmospheric probes, ...) identification of atmospheric hazards, and their correlation and merging. The Navigation Display should provide a congruous and accurate visualization of these new weather information products, among other functionalities related to terrain and traffic hazards developed in the Flysafe framework, while offering a flexible interface to pilots.
Meso-NH simulations directly feed the ADWR database which includes outputs listed in Table 1. Additional meteorological parameters (turbulence, pressure, temperature,... see Table 1) are also needed by the FFS in order to feed the aerodynamic simulation and the cockpit instruments displays. During each 5-min interval, the ADWR simulator interpolates the meteorological data between the previous and the next snap shot. The ADWR simulator considers the model-derived reflectivity fields to obtain synthetic onboard radar observations by assuming a conical radar beam with a given aperture. Within each resolution volume, several points are taken from the reflectivity field. These points are normally distributed along the radar beam cross-section, in order to represent the antenna power distribution. The reflectivity values of resolution volumes are presented on the Navigation Display as a color-coded map. An example of such a radar image can be seen in Fig. 4. With the use of a terrain-masking model, the ADWR simulator is also able to compute the ground returns of the radar beam (not shown). The ADWR can estimate wind speed along the radar beam in precip-

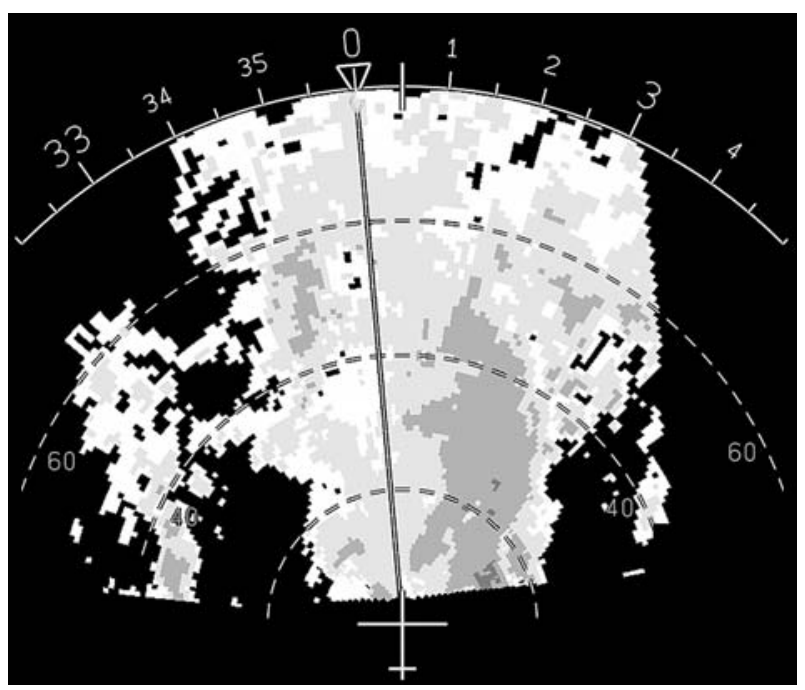

Fig. 4. Example of an ADWR simulation computed from Meso-NH data, visible on the Navigation Display. Shades of grey represent the reflectivity field: white, light grey, grey, and dark grey indicate reflectivity values between 20-30, 30-40, 40-50, and 50-70 dBZ, respectively. The scale in the top gives the aircraft heading $\left(10^{\circ}\right.$, angle between north and direction that the aircraft's nose is pointing). Here, the aircraft is flying northward at $3 \mathrm{~km}$ altitude. The ranges of the radar (white dashed arcs) are given in nautical miles 
itating areas: this information is used to predict wind shear hazards within the radar range. Depending on the location of the predicted wind shear, the ADWR issues a caution or a warning message.

\section{Weather information management systems: CB and ICE WIMSs}

WIMSs are designed to improve the pilot awareness of weather hazards. They are implemented for three scales: the TMA, the regional and the global scales. This partitioning has been determined in order to take into account the different demands on meteorological information at these scales. Also, the observation data availability varies strongly among these scales. Hazards information is delivered using object-based models specific to each area, implemented on-ground and generating value-added products from observations and model forecasts. Thereafter, description of the baseline version of $\mathrm{CB}$ and ICE WIMS on TMA scale is given, as well as their results for the Innsbruck case.

\section{CB WIMS}

The baseline CB WIMS implementation delivers a representation of observed and nowcast thunderstorm-related hazards through hazard objects for two layers: the upper and lower parts of the cumulonimbus $(\mathrm{Cb})$, named $\mathrm{Cb}$ top volume and $\mathrm{Cb}$ bottom volume, respectively. The bottom volume represents the aircraft related hazard's heavy precipitation, hail, in-flight icing, lightning and wind shear in the lower part of thunderstorms, i.e. the convective updraft region, while the top volume addresses the hazard's lightning and turbulence in the upper anvil region.

The $\mathrm{Cb}$ top volumes are determined by the thunderstorm tracking and monitoring $(\mathrm{Cb}$ TRAM) tool, a new fully automated algorithm for the detection and nowcasting of convection (Zinner et al. 2008). Originally, the detection is based on Meteosat SEVIRI (Spinning Enhanced Visible and IR Imager) data from the broad-band high-resolution visible (HRV), WV $6.2 \mu \mathrm{m}$, and IR $10.8 \mu \mathrm{m}$ channels. These channels are combined to identify three different stages of thunderstorm development: areas with convection initiation, with rapid vertical development, and with mature thunderstorm cells. For the latter, lapse rate tropopause temperatures (WMO 1957) are derived from ECMWF operational model data (ECMWF 2005) and used as an adaptive detection criterion for convective cloud tops. This stage is taken to represent the $\mathrm{Cb}$ top volume. $\mathrm{Cb}$ TRAM can detect convective updrafts within thunderstorm complexes by exploring the roughness of the satellite image in the HRV. This has been shown to improve considerably the detection. The tracking is based on the geographical overlap between current detections and first guess patterns of cells detected in preceding time steps. The first guess patterns are retrieved by using the approximate moving direction and velocity of a detected cloud pattern at time $t-1$ (with $t=$ current time) in combination with a new so-called pyramidal image-matching algorithm (Zinner et al. 2008). This algorithm extracts the general transformation vector field from two consecutive satellite images thereby describing the cloud motion and local cloud developments. Similar to the first guess patterns, nowcasts (short range forecasts) up to $60 \mathrm{~min}$ are generated by extrapolation and use of the pyramidal imagematching algorithm. For this test-bed concept, Cb-TRAM was applied to synthetic satellite data for the first time. Synthetic WV and IR data based on Meso-NH simulations were used instead of Meteosat data. In addition, the lapse rate tropopause temperatures were derived from the Meso-NH temperature fields. Otherwise, no changes were made in Cb-TRAM. However, the HRV information is missing in the detection since there was no synthetic Meso-NH data available for the visible channel. Therefore, updraft regions cannot be isolated and the diagnosed top volumes might be somewhat larger than with the usual detection procedure which uses also the visible channel. Figure 5a shows Meso-NH IR brightness temperatures together with diagnosed and nowcasted mature thunderstorm cells $(\mathrm{Cb}$ top volumes, isolines) computed by $\mathrm{Cb}$-TRAM at 1400 UTC on 20 September 1999. The top volume is detected in areas with low IR temperatures (darker shades of grey). The grey and light grey contours in Fig. 5a represent the 5 and 10 min nowcasts, respectively. These nowcasted objects are displaced north-eastward in relation to the reference dark grey object, in agreement with the south/south-westerly upper-level flow, and the temporal evolution of upper-level clouds 


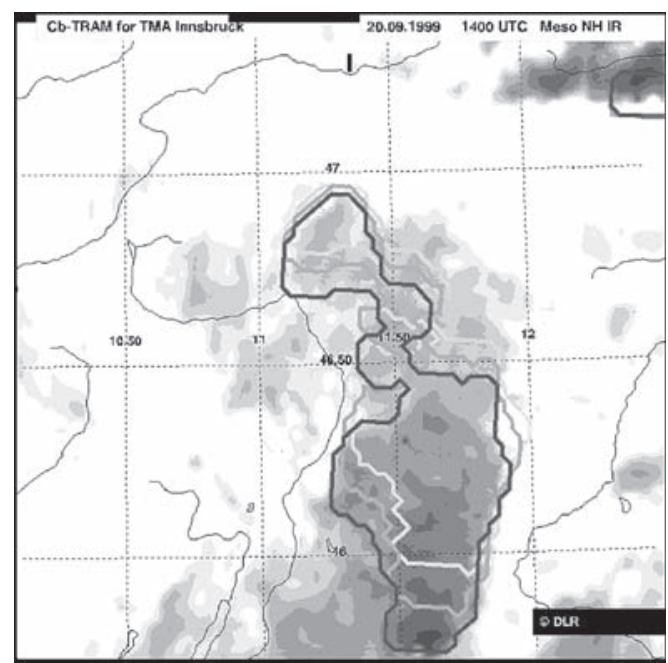

a

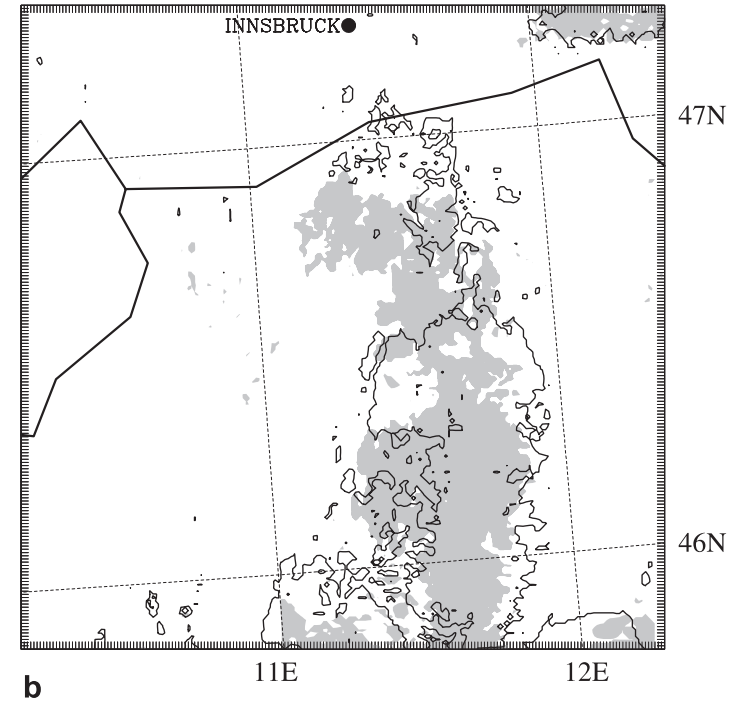

b

Fig. 5. (a) Cb-TRAM Cb top volume diagnostic (dark grey isocontour) and nowcasts at 5 and 10 min (grey and light grey isocontours, respectively) on Meso-NH IR synthetic satellite data over the Innsbruck TMA at 1400 UTC on the 20 September 1999. Darker shades of grey indicate low temperatures. Innsbruck airport is marked by letter I. (b) Meso-NH cloud top height higher than $11 \mathrm{~km}$ altitude at 1400 (grey area) and 1410 UTC (black isoline)

simulated by Meso-NH between 1400 and 1410 UTC (Fig. 5b). This indicates that the Cb-TRAM algorithm successfully works with the Meso-NH synthetic satellite data and provides valuable nowcast.

$\mathrm{Cb}$ bottom volumes processing is based on radar reflectivity data. The main diagnostics are made with the COnvection Nowcasting Objects (CONO) tools (Hering et al. 2005) which implement real-time object-oriented interpretation of radar data, in order to automatically identify and track convective cells and/or convective systems. The CONO detection method is based upon an adaptive reflectivity thresholding, derived from the algorithms developed for the severe thunderstorms satellite nowcasting product Rapid Developing Thunderstorms (RDT, Morel et al. 2002). The TMA mode provides forecasts at a one-hour forecast range with a 5-min time step for the first half hour, and 15-min thereafter.

For the simulation of $\mathrm{Cb}$ bottom volume products, the Meso-NH diagnostic package provided two-dimensional (2D) fields (Table 1): (i) Zmax: maximum reflectivity for each vertical column, (ii) Htop: highest altitude where the 18-dBZ reflectivity level is encountered, and (iii) VIL: Vertically Integrated Liquid water content. In the present stage of CB WIMS development, Zmax reflectivity is used to define 30 - and 40-
dBZ level contours for defining hazard objects, while Htop will contribute to describe the hazard objects vertical extension, and VIL is considered as an alternate basic parameter for defining their horizontal extension. The current practice is to use a color-coding scheme showing levels above $30 \mathrm{dBZ}$ in yellow and above $40 \mathrm{dBZ}$ in red. Rhoda et al. (2002) showed that 40-dBZ reflectivity levels represent a major threat for aircrafts. Areas with reflectivity above $40 \mathrm{dBZ}$ are generally avoided during the en-route flight phase, while constraints linked to the approach phase may drive the pilots to penetrate these areas. Reflectivity levels of $30 \mathrm{dBZ}$ are avoided when few constraints apply to the flight path. Figure 6 shows an example of the CONO tracking system output for the MAP-IOP2B case at 1400 UTC. Objects computed for the 30- and 40-dBZ reflectivity levels (contour lines on Fig. 6a and b, respectively) are drawn on the Meso-NH maximum reflectivity field. It can be seen that the CONO algorithm correctly detects cells contour for the two thresholds. The diagnostic tracking is also coherent with the main flows. The 30-dBZ object (Fig. 6a) has a north/north-eastward motion in accordance with the mid-level southerly flow. Using the 40-dBZ threshold leads to refine the diagnostic: individual active cell movements within the overall large precipitating system dis- 

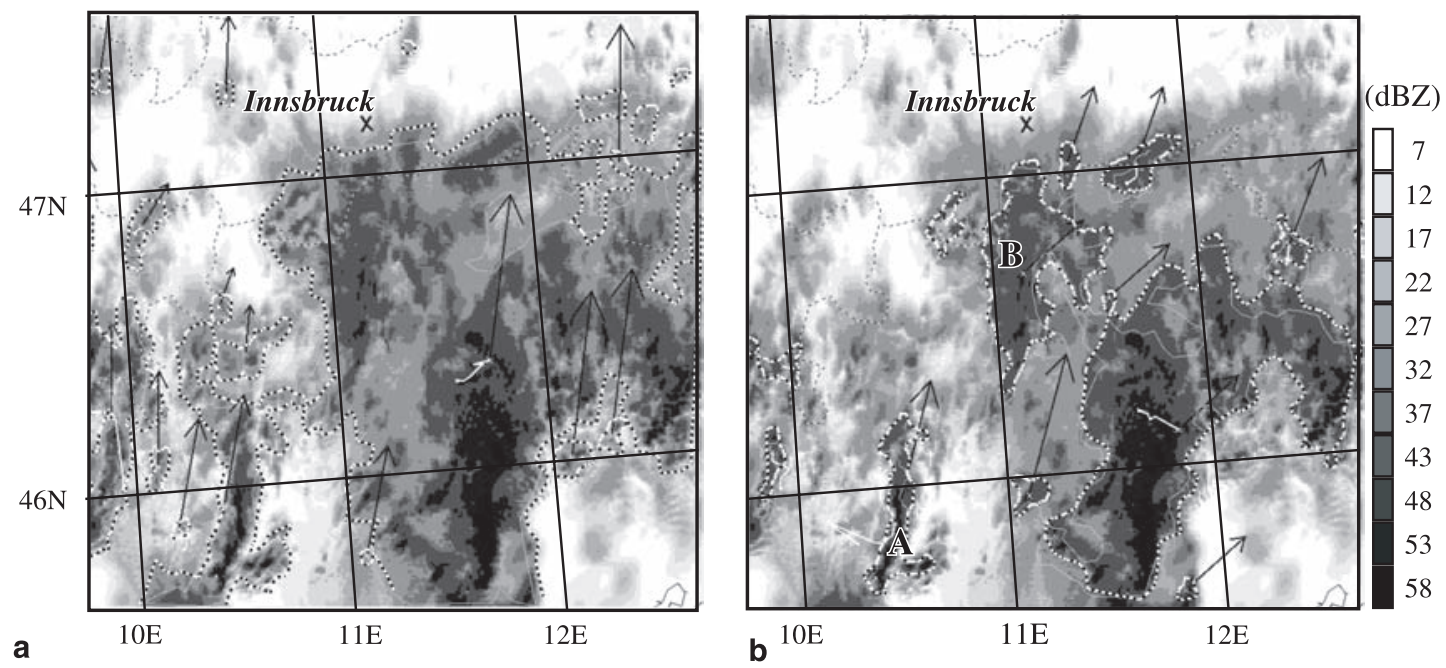

Fig. 6. CONO results over the $1 \mathrm{~km}$ model domain at 1400 UTC on 20 September 1999 with a reflectivity threshold (thick dashed contours) of (a) $30 \mathrm{dBZ}$ and (b) $40 \mathrm{dBZ}$. The object's gravity center track is indicated in white. Black vectors give objects motion direction. Labels A and B are referred to in the text. The black cross marks the location of Innsbruck

placement appear. In particular, orographic effects on the cell motion are evidenced, such as the channelling by the main valley (A) and the deflection due to high summits (B). Work is nonetheless underway to assess the quality of the extrapolation based on such displacement diagnostics, especially when the $40-\mathrm{dBZ}$ threshold is considered.

\section{ICE WIMS}

Météo-France has developed a system for the identification of in-flight icing areas, named SIGMA (System of Icing Geographic identification in Meteorology for Aviation) (Le Bot 2004). This is the ICE WIMS precursor system from which a baseline version at TMA scale has been developed. This baseline system is based on the merging of three sources of data: (i) an icing risk index calculated from the French Numerical Weather Prediction model ALADIN (Aire Limitée, Adaptation dynamique, Développement InterNational) (Fischer et al. 2006), which has a resolution of $0.1^{\circ}$, i.e., $\sim 10 \mathrm{~km}$; (ii) the Meteosat8 IR brightness temperatures (4 $\mathrm{km}$ resolution); (iii) the $2 \mathrm{D}$ reflectivity from the French operational radar network (1 km resolution). Each piece of data can confirm or invalidate information deduced from the others. The algorithm is based on the warm cloud-tops theory (Pobanz et al. 1994). The IR satellite imagery is first used to identify the cloudy areas. Icing risk depends on cloud top temperature. The $0{ }^{\circ} \mathrm{C}$ to $-18^{\circ} \mathrm{C}$ range presents the highest risk of severe icing due to super-cooled water presence. The additional information provided by the icing index is then taken into account. It defines the areas where both humidity and temperature conditions are favourable to icing, for each vertical model level separately. Finally, radar information is used to identify the presence of precipitation or, in case of weak radar echoes, the possibility that droplets are suspended in the air. The algorithm produces 3D grid point data, which shows cloudy areas having humidity and temperature conditions favourable to icing, using four different severity levels. These intensity levels are defined as follows: low icing risk, moderate, high, and high with Supercooled Large Droplets (SLD). These data are then converted to 2D objects indicating icing intensity on pressure vertical levels (from 1000 to $400 \mathrm{hPa}$ each $50 \mathrm{hPa}$ ). The algorithm runs every $15 \mathrm{~min}$ with a horizontal resolution of about $1 \mathrm{~km}$ centred on a given TMA.

For the test-bed framework, the baseline ICE WIMS has been modified to enable the use of synthetic data from Meso-NH simulations inputs, instead of radar and satellite observations. ICE messages diagnosed from Meso-NH synthetic data (Table 1) show a large area of high icing covering most of the domain (Fig. 7a). This large extent is explained by relative humidity greater than $80 \%$ over all this area, coinciding with negative temperatures (Fig. 7b), and/or significant simulated radar reflectivities (Fig. 3). In the 

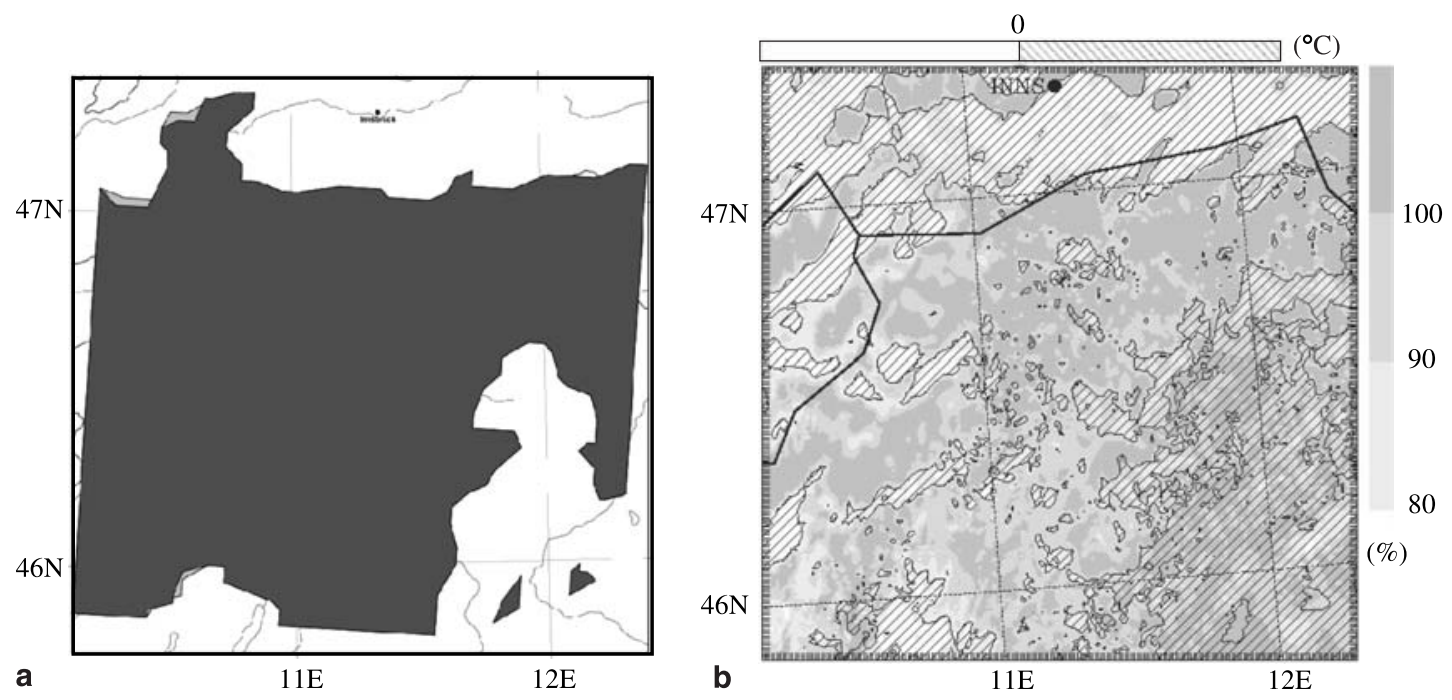

Fig. 7. (a) ICE WIMS diagnostics over TMA area at $650 \mathrm{hPa}$ at $1400 \mathrm{UTC}$ on 20 September 1999. Icing risk is represented in grey scale with 2 levels: moderate (light grey) and high (dark grey). (b) Meso-NH fields at $650 \mathrm{hPa}$ of relative humidity $(\%)$ and temperature $\left({ }^{\circ} \mathrm{C}\right)$ at 1400 UTC on 20 September 1999

ICE WIMS algorithm, the presence of rain greatly enhances the severity of the diagnosed icing because of the aerosols washout process. The right agreement between the simulated satellite IR temperature and the humidity fields, as well as the surface temperature is warrant of the algorithm good coherence. On the vertical, significant icing risks extend from 650 to $450 \mathrm{hPa}$ for the whole period, corresponding to the layer with temperature between 0 and $-20^{\circ} \mathrm{C}$.

\section{Conclusions and outlook}

This paper deals with one of the European actions to maintain and improve the air safety regarding weather hazards within the Flysafe project. One of the Flysafe aims is to improve the meteorological information relayed to the cockpit. To reach this goal, a new integrated surveillance system was developed: the NG-ISS, which combines value-added data related to weather, terrain and traffic hazards. New information messages devoted to weather hazards were defined: the WIMS products. Diagnostics of ICE and CB WIMSs, warnings related to in-flight icing and thunderstorm risks, were described for the configuration peculiar to the airport approach (TMA mode).

This study presents the use of numerical weather simulations in a full flight simulator test-bed, including the NG-ISS and WIMS mes- sages. In the frame of the NG-ISS evaluation phase, convective-scale atmospheric model Meso-NH and GRACE flight simulator are used together. Meso-NH simulations provide the meteorological environment needed by the flight simulator. They also feed tools that issue both standard meteorological products for aviation and WIMS messages.

This test-bed set-up will allow to test whether it is technically feasible to provide new weather information from the ground (WIMS product) to the cockpit and merge it with onboard data in real time. From a meteorological point of view, this set-up ensures the consistency of all information flows: a numerical simulation of severe weather is the only source for all components of meteorological products in the cockpit, WIMS as well as onboard radar or atmospheric probes information. This enables a coherent comparison between each individual meteorological product. For the specific case of MAP-IOP2B precipitating event, pilots in the FFS will be able to evaluate the usefulness of the new weather products for a typical hazardous flight situation, where both terrain and weather come into play. Though this study is essentially focused on hazards related to thunderstorm and in-flight icing, it is also conceivable to deal with others aspects of this IOP, like Foehn or gravity waves. More generally, MAP campaign constitutes a valuable database to perform further evaluations. 


\section{References}

ACARE, Advisory Council for Aeronautics Research in Europe (2002) Strategic Research Agenda 1, Vol. 2: The challenge of safety. www.acare4europe.com/html/ documentation.asp

Asencio N, Stein J, Chong M, Gheusi F (2003) Analysis and simulation of local and regional conditions for the rainfall over the Lago Maggiore target area during MAP IOP $2 \mathrm{~b}$. Quart J Roy Meteor Soc 129: 565-86; DOI: 10.1256/ qj.02.37

Bougeault P, Binder P, Buzzi A, Dirks R, Houze R, Kuettner J, Smith RB, Steinacker R, Volkert H (2001) The MAP special observing period. Bull Amer Meteor Soc 82: 3433-62; DOI: 10.1175/1520-0477(2001)082< 0433:TMSOP $>2.3 . \mathrm{CO} ; 2$

Chaboureau J-P, Bechtold P (2005) Statistical representation of clouds in a regional model, and the impact on the diurnal cycle of convection during TROCCINOX. J Geophys Res 110: D17103; DOI: 10.1029/2004JD005645

ECMWF (2005) MARS User Guide European Center for Medium Range Weather Forecast - ECMWF, Reading, UK; Manual available at www.ecmwf.int/publications/ manuals/mars /

Fischer C, Montmerle T, Berre L, Auger L, Stefanescu SE (2006) An overview of the variational assimilation in the ALADIN/FRANCE NWP system. Quart J Roy Meteor Soc 613: 3477-92; DOI: 10.1256/qj.05.115

Heesbeen WWM, Ruigrok RCJ, Hoekstra J-M (2006) GRACE - a versatile simulator architecture making simulation of multiple complex aircraft simple. Proc. AIAA Modeling and Simulation Technologies Conference and Exhibit, 21-24 August 2006, Keystone, CO, USA

Hering A, Sénési S, Abrosetti P, Bernard-Bouissières I (2005) Nowcasting thunderstorms in complex cases using radar data. WMO Symp. on Nowcasting and Very Short Range Forecasting, Toulouse, France

Jaubert G, Stein J (2003) Multiscale and unsteady aspects of a deep Foehn event during MAP. Quart J Roy Meteor Soc 129: 755-76; DOI: 10.1256/qj.02.38

Lafore JP, Stein J, Asenscio N, Bougeault P, Ducroq V, Duron J, Fischer C, Héreil P, Mascart P, Masson V, Pinty
J-P, Redelsperger J-L, Richard E, Vilà-Gureau de Arellano J (1998) The Meso-NH atmospheric simulation system. Part I: Adiabatic formulation and control simulations. Ann Geophys 16: 90-109

Le Bot C (2004) SIGMA: system of icing geographic identification in meteorology for aviation. Abstracts of 11th Conf. on ARAM, AMS, Hyannis, MA

Morel C, Sénési S, Autones F (2002) Building upon SAFNWC products: use of the Rapid Developing Thunderstorms (RDT) product in Météo-France nowcasting tools. Proc., The 2002 Meteorological Satellite Data Users Conference, Eumetsat and Met. Eirean, Dublin, Ireland, pp. 248-55

Pobanz B, Marwitz JD, Marcia K. Politovich (1994) Conditions Associated with large-drop regions. J Appl Meteorol 33: 1366-72; DOI: 10.1175/1520-0450(1994)033<1366: CAWLDR $>2.0 . \mathrm{CO} ; 2$

Rhoda DA, Kocab EA, Pawlak ML (2002) Aircraft Encounters with Thunderstorms in En-route vs. Terminal Airspace above Memphis, Tennessee. 10th Conf. on Aviation, Range, and Aerospace Meteorology, Portland, Oregon, May 13-16, AMS

Richard E, Cosma S, Tabary P, Pinty J-P, Hagen M (2003) High-resolution numerical simulations of the convective system observed in the Lago Maggiore area on 17 September 1999 (MAP IOP2a). Quart J Roy Meteor Soc 129: 543-63; DOI: 10.1256/qj.02.50

Rotunno R, Houze RA (2007) Lessons on orographic precipitation. Quart J Roy Meteor Soc 133: 811-30; DOI: 10.1002/qj.67

Smith RB, Jiang Q, Fearon MG, Tabary P, Dorninger M, Doyle JD, Benoit R (2003) Orographic precipitation and air mass transformation: an Alpine example. Quart J Roy Meteor Soc 129: 433-54; DOI: 10.1256/qj.01.212

WMO (World Meteorological Organisation) (1957) Meteorology: a three-dimensional science 230. WMO Bull 6: 134-8

Zinner T, Mannstein H, Tafferner A (2008) Cb-TRAM: tracking and monitoring severe convection from onset over rapid development to mature phase using multi-channel Meteosat-8 SEVIRI data. Meteorol Atmos Phys 101: $191-210$ 